\title{
O traço da distinção: discutindo entendimentos sobre arquivos e memória
}

\section{Taiguara Villela Aldabalde}

Universidade Federal do Espírito Santo (UFES)

\section{Maira Cristina Grigoleto}

Universidade Federal do Espírito Santo (UFES)

\section{Resumo}

Este artigo apresenta, reflexões acerca da articulação entre arquivo e memória. A partir da problemática em torno do uso dos termos arquivo e memória como sinônimos, busca entendimentos sobre as formas de alocação, fundamentação e acomodação para esta utilização. Resultado de pesquisas teórica e documental aborda, com base na Arquivística e na episteme científica, elementos que validam esta articulação. Nesse sentido, trata-se a questão da exteriorização, materialização e institucionalização de memórias em lugares pré-definidos, os reconhecidos lugares de memória. Em decorrência, direciona a análise da relação entre arquivo e memória a partir de três categorias: o documento de arquivo tradicional, o arquivo eletrônico e o fundo de arquivo. Conclui que as relações possíveis entre memória e arquivo se estabelecem por meio das associações com os saberes e as práticas da Arquivística.

Palavras-chave: Arquivo; Memória; Lugares de mémória.
The trace of distinction: discussing understandings about archives and

memory

\section{Abstract}

This article presents reflections about the articulations between archive and memory. From the problems surrounding the use of the terms archive and memory as synonyms, search understandings about the forms of allocation, grounding and accommodation for this utilization. The results of theoretical and documentary research based on the archivistics and on the scientific episteme validate this articulation. In this sense, the approach includes the externalization, the materialization and the institutionalization of memories in predefined places, recognized as places of memory. As a result, we direct the analysis of the relationship between archive and memory from three categories: the traditional archival document, the electronic record and the funds. It concludes that the possible relationships between memory and archive are established through associations with archival knowledges and practices.

Keywords: Archive; Memory; Places of Memory. 


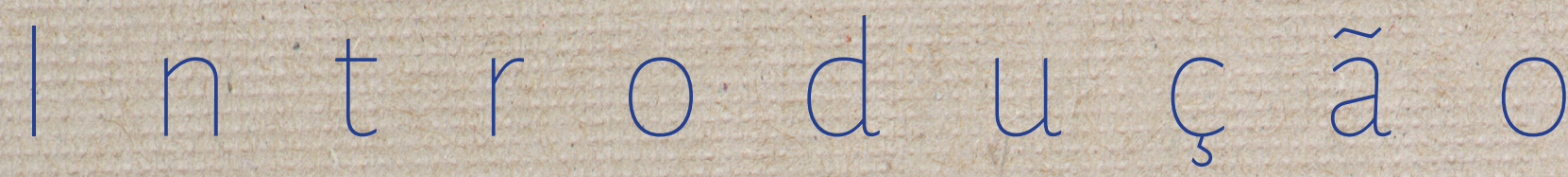

A importância atribuída aos baús e depósitos de armas contendo documentos que eram muitas vezes chamados de "arca" o "archivum" - é também atestado pelo cuidado tomado em decorá-los: Duccio di Boninsegna e Ambrogio Lorenzetti estavam entre os famosos pintores contratados para esse trabalho. O ditado medieval "castrum sine armario est quasi castrum sine armamentario" (isto é, um castelo sem arquivos é um castelo sem equipamento) revela a centralidade do lugar "arquivos" em cada complexo arquitetônico (DURANTI, 2007, p. 450-457, tradução nossa).

A proposta de pensar o uso das palavras arquivo e memória como sinônimas conduziu-nos para a busca por entendimentos sobre as formas de alocação, fundamentação e acomodação desta utilização.

Desde o início, constatamos que tais palavras não são sinônimas, mas que passaram a ser identificadas e utilizadas como tal, seja em "comunicações comuns" ou mesmo pelos "arquivistas de maneira muito confiada e muito frequentemente" (PICCOTT, 2007, p.
405, tradução nossa). De certa forma, foram incorporadas em decorrência de diferentes associações, as quais nem sempre são enunciadas e fundamentadas. Este fato oculta os múltiplos significados destes termos, os quais são fundamentais para uma articulação mais ampla e qualificada, resultando em usos e conexões exageradas (PICCOTT, 2007).

No sentido de contribuir com reflexões mais bem fundamentadas sobre a possibilidade de estabelecer a articulação entre arquivo e memória buscamos tratar esta problemática a partir do campo da Arquivística e pela episteme científica. Esse campo tem se consolidado na América Latina tanto pelo termo arquivística/archivistica quanto arquivologia/ archivología ao passo que nos países francófonos e na Espanha mantém-se o termo archivistique. Já nos países anglófonos há ocorrência de archival science, archivistics e archival studies. De 
maneira sintética, entendemos a Arquivística como a ciência dos arquivos (CASANOVA, 1928). ferenciais, o que coloca em evidência as conjunturas para a validação, manutenção e atualização deste vínculo. ,

Deste modo, em um primeiro momento tratamos a questão da exteriorização, materialização e institucionalização de memórias em lugares pré-definidos, os reconhecidos lugares de memória. Esta

\section{Arquivos e memórias: o traço da distinção}

primeira reflexão possibilitou a constatação de que, em certa medida, arquivo e memória se acham em inter-relacionamento.

Para ele, a palavra arquivo deriva do grego archeion que, por sua vez, significa um lugar onde documentos legais

Para fundamentar tal verificação, optamos por apresentar nossa análise a partir de três categorias: o documento de arquivo tradicional, o arquivo eletrônico e o fundo de arquivo. Pelo pensamento dos arquivos como fontes e capacitores de poder(es), verificamos que a articulação entre arquivo e memória se estabelece a partir de manifestações temporais (mnemônicas) em lúgares, espaços e ambiências di-
Pelo pensamento dos arquivos como fontes e capacitores de poder(es), verificamos que a articulação entre arquivo e memória se estabelece a partir de manifestações temporais (mnemônicas) em lugares, espaços e ambiências diferenciais, o que coloca em evidência as conjunturas para a validação, manutenção e atualização deste vínculo. eram recolhidos. 0 autor destaca que os arquivos passaram a ter valor probatório no âmbito judicial somente a partir do ordenamento de Justiniano, isto é, em 534 d.C. Long (1845) sublinha que entre os romanos os arquivos eram depositados em templos e, mais particularmente, no templo de Saturno, irmão de Mnemosyne, onde o tesouro público era guardado. Mnemosyne, deusa da me- 
mória e, dentre outras coisas, responsável pelo progresso das ciências. Há ainda outra distinção que julgamos ser preciso pontuar: no contexto da república romana, o termo tabularium era aplicado aos documentos de um modo geral, mas o termo archivum era associado ao lugar de depósito dos documentos para a preservação.

Feitas estas observações preliminares sobre a alocação das origens possíveis e dos significados dessas palavras, é possível constatarmos que é equivocada a ideia de que arquivo é sinônimo de memória. Esse equívoco, a nosso ver, se dá em decorrência do uso impreciso dos termos arquivo e memória ou das acomodações que assumiram ao longo dos tempos. Para nós, é preciso entender que essas palavras não são sinônimas, mas que passaram a ser associadas entre si, carregando múltiplos sentidos a partir de diferentes relações e usos. Além disso, pode-se pensar que tais associações é que foram criando aproximações e entendimentos de forma que, em muitos casos e esferas, culminou no tratamento e utilização destes termos como sinônimos.
O termo arquivo pode significar usualmente, dentre outras acepções: um documento eletrônico; um conjunto de, documentos arquivísticos; umúnico documento (unidade documental); uma instituição arquivística; um móvel para armazenamento e acondicionamento; um setor de uma empresa. A memória, por sua vez, tem sido objeto de pesquisa de diversas áreas do conhecimento, dentre as quais destacam-se: História, Sociologia, Psicologia, Biologia, Filosofia, Informática, Genética, Neurociência e Medicina.

A precisão no uso dos termos arquivo e memória depende do contexto em que é estabelecido o seu tratamento e entendimento. No entanto, sempre há distinção entre os conceitos. Podemos pressupor, por exemplo, que no contexto da Psicogenealogia a memóriá esteja sob a perspectiva da Psicologia; ao mesmo tempo em que o arquivo adquire o significado de conjunto documental com dados pessoais, genealógicos e familiares. A memória, mesmo tomada como objeto da Psicologia, Neurociência e Medicina, não está encerrada no cérebro, porque há extensões do cérebro, 
por exemplo, com as nossas anotações, manuscritos e demais registros.

A questão da exteriorização, materialização e institucionalização da memória é um ponto de observação a partir do qual podemos conduzir alguns entendimentos sobre as possíveis relações constituídas entre arquivos e memória. Deste modo, recorremos à conhecida colocação de Nora (1993, p. 8): "se ainda habitássemos a nossa memória não teríamos necessidade de lhe consagrar lugares".

Como analisado por Meneses (2007, p. 31), o historiador francês tratou a mudança de ambientes de memória para os lugares de memória. Nora (1993) considerou, portanto, a transformação progressiva entre a memória espontânea, viva, realizada, experiência internalizada, para uma memória que se dá fora das pessoas, fora da experiência individual e interiorizada. Nesse sentido, o ponto por ele tratado é que, a partir do século XVIII, não foi mais possível pensar a memória da mesma maneira, pois esta passou a ser reconhecida a partir de outras perspectivas, no sentido da ampliação do reconhecimento e validação dos suportes de memória.
Desde o século XVI, verifica-se esse processo de transformação vinculado aos progressos da memória escrita (LE, COFF, 2003). A questão apontada por Nora (1993) está, portanto, nas novas formas de reconhecimento que estas evidências, que as memórias e experiências, assumiram mediante processos de exteriorização, materialização e institucionalização.

Para Meneses (2007, p. 31), Norá (1993) analisa a mutação da memória do interior para o exterior e é nessa dinâmica, e somente considerando essa dinâmica, que podemos pensar e falar sobre lugares de memória. Na concepção do historiador brasileiro, "a memória 'viva' não desapareceu, assumiu outras possibilidades que vão além dos lugares de memória". A memória individual existe, mas é inacessível e, só quando se socializa, é que ela pode aparecer.

Com relação à materialização desta exteriorização/socialização, Meneses (2007, p. 31) apresenta que "a memória é um processo que depende, sim, de suportes objetivos, porém não se confunde com eles". A aproximação entre a memória e os suportes de memória dependerá 
da intenção e das circunstâncias que configuram tal vinculação/alocação.

Segundo Dodebei e Couveia (2008), as memórias auxiliares, ou próteses, funcionam para compensar a dinâmica da memória individual, que não pode abrir mão do esquecimento. Um exemplo que ilustra esta questão pode ser verificado no âmbito do Arquivo $\mathrm{Na}$ cional da Austrália que, no intuito de apresentar sua proposta de gestão de registros a agências de governo, elaborou um pôster. Neste, estava escrito Conserva um Registro e como ilustração havia a imagem de um elefante. $O$ texto que acompanhava o pôster trazia a seguinte explicação: "Dizem que os elefantes nunca esquecem, o que, se for verdade, seria de grande ajuda para conservar registros. Porém, o recordar humano é menos fiável, assim, necessitamos armazenar informação" (PICGOTT, 2007, p. 408, tradução nossa).

Le Coff (2003, p. 449-450), a partir da doutrina clássica dos lugares e das imagens, apresenta que foram formuladas regras mnemônicas que tratam da necessidade de se encontrar" simulacros adequados das coisas que se deseja recordar" ou "inventar simulacros e imagens porque as intenções simples e espirituais facilmente se evolam da alma, a menos que estejam, por assim dizer, ligadas a qualquer símbolo corpóreo"; e, em seguida, dispor "numa ordem calculada as coisas que se deseja recordar de modo que, de um ponto recordado se torne fácil a passagem ao ponto que lhe sucede".

Nessa perspectiva, os registros, os documentos de arquivo e os arquivos podem vir a ser ativadores da memória, ao mesmo tempo em que aquilo que lembramos pode fixar-se no espaço/tempo do registro como ideia sobre um fato passado. Isso quer dizer que os arquivos são fontes/suportes/próteses para a memória e que a lembrança depende de bases materiais e elementos imateriais para perpetuar-se. Assim, constatamos que, em certa medida, o arquivo e a memória se acham em inter-relacionamento.

Sobre práticas e entendimentos: uma proposta de discussão

Considerando que as práticas mnemô- 
nicas são instrumentais para a ativação das memórias e que estas estão mais próximas dos contextos das significações diversas para o termo arquivo, optamos por apresentar nossa análise a partir de três categorias: o documento de arquivo tradicional, o arquivo eletrônico e o fundo de arquivo.

É preciso, antes de tudo, localizar no tempo e no espaço que o material de arquivo foi, na doutrina arquivística mais antiga, estudado e reconhecido desde o séculoXVI por Jacob von Rammingen, na obra Sobre o protocolo de registro, de 1571. Mais, destacar que 0 termo registro original, em alemão registratur, corresponde ao francês registre e ao italiano protocolo/registratura, porque esses conceitos são associados a uma parcela significativa de práticas que, até os dias de hoje, são comuns aos arquivos: receber, registrar, controlar, produzir, acumular, recuperar e organizar determinados documentos.

E que documentos seriam esses? Ora, a natureza do material de arquivo é sua forma congênita em um determinado contexto e sentido original vinculados com o produtor. A gênese de um arquivo é decorrente de umà ação geradora, de tal maneira ligada à pessoa ou instituição produtora, que constitui naturalmente uma acumulação sedimentá-, ria oriunda. Os arquivos são, portanto, aqueles que, entre outras categorias de documentos, podem ser classificados como fontes primárias; já que é possível reconhecer, quando respeitados os princípios arquivísticos, na sua própria anatomia a vinculação direta com a lógica do organismo gerador.

Um caso concreto para entender esse vínculo é o estudo de arquivos manuscritos. Fernando Pessoa (1888-1935), por exemplo, deixou um legado de quase 30.000 peças documentais que pode ser explorado por diversas técnicas: a documentoscopia, a crítica diplomática, a análise tipológica, a grafotécnica, a grafoscopia e a paleografia contemporânea. Todas essas técnicasciências, reunidas com um corpo interdisciplinar de especialistas das ciências da mente e da literatura, poderiam revelar poemas antes não compreendidos devido ao difícil reconhecimento da caligrafia, termos, conceitos e forma de escrita hermética e até revelar o estado emocional do autor ou traços de sua personalidade. 
É possivel entender que um livro de bolso de Fernando Pessoa (18881935), publicado hoje, possui uma relação mais distante do autor/produtor e jamais superaria a proximidade de Pessoa comseus próprios manuscritos. Assim, 0 arquivo pessoal de Fernando Pessoa não é a memória do autor, mas se trata do conjunto dos documentos produzidos (manuscritos), recebidos (como as cartas que constituíram o Dossiê Crowley-Pessoa) e acumulados (como aqueles envelopes que se achavam na arca onde Pessoa ordenava originalmente uma parte significativa de seus trabalhos).

Além de fontes primárias para os estudiosos ou pesquisadores, os arquivos são provas. Para pensarmos isso basta observarmos que o nosso Estado só atende plenamente os direitos de um cidadão a partir de seus documentos básicos como: certidão de nascimento, cédula de identidade e cadastro de pessoa física. O cidadão que não se inscreve nesses arquivos será, em grande medida, socialmente marginalizado, tendo direitos negados. Ter os dados pessoais inscritos no arquivo é uma pré-condição para a inserção na vida cultural, burocrática. Essa vida oficializada permite racionalizar as trocas, obter os prejuízos, as vantagens, usufruir de direitos, interagir com outras sociedades burocratizadas, progredir pelas instituições, explorar o trabalho alheio ou ofertar seu tempo de vida para trabalhar. Para que o documento de arquivo seja ativado como dispositivo confiável, é preciso preservar a sua essência: a capacidade de provar algo.

Assim, os arquivos são fontes de poder por meio das quais se legitimam as autoridades, se reconhecem os cidadãos e se oficializam todos os atos na sociedade. A civilização ocidental moderna permite ser conhecida, com mais ou menos restrições, em vários aspectos devido a preservação dos arquivos. As hierarquias sociais, por exemplo, estão representadas e podem ser reconhecidas em registros contábeis, militares, ultrassecretos, governamentais, clericais, bancários e'empresariais.

Se o Estado é capaz de impor uma multiplicidade de deveres em relação aos documentos, inclusive aos grupos 
que antecedem a essa lógica - como os ciganos, que muitas vezes optam pelo analfabetismo -, então, também é preciso pensar o que significam esses grupos, e até uma civilização, sem registros para o tempo presente. Como seria possivel reconhecer, através da ciência, a existência de grupos ou de uma civilização de pessoas que não deixaram suas marcas, seus registros ou seus arquivos? Tais grupos poderiam, no máximo, ser lembrados como uma categoria lendária, tal como os hiperbóreos descritos nas teorias platônicas.

A preocupação com a materialidade dos documentos de arquivo e sua capacidade de provar algo está associada ao saber científico. Os arquivos são dispositivos da racionalização e permitem, por meio de um sistema burocrático, 0 uso desses conjuntos documentais por parte dos cientistas para alcançar resultados (LATOUR, 2011). Esses resultados adquirem cientificidade justamente porque podem ser amplamente verificados, isto é, o acesso aos arquivos pode permitir um escrutínio sobre a metodologia. A verificabilidade, que é um dos critérios para definir ciência, pode ser comprometida, em certa medida, caso não se respeite as quali-, dades dos arquivos, como a autenticidade, a identidade e a integridade. A Diplomática e a Tipologia Documental são as principais disciplinas no campo do saber arquivístico ligadas com a preservação e análise dessas qualidades. Em resumo, é relevante para cientistas o conhecimento da maneira como os documentos têm sido produzidos, classificados e interligados, pois os métodos que levaram aos resultados estão registrados na documentação que pode ser revisitada e distintamente combinada no sentido de gerar novos resultados (LATOUR, 2011).

Desde a época de Tales de Mileto, isto é, considerando o intervalo de 624 até 546 a.C., já era do saber dos antigos astrônomos que era possível prever eventos. Logo, a ligação com a ciência não é moderna, pois a previsão de eventos futuros baseada no comportamento dos astros só foi possível mediante o uso de registros de observação. Uma expressiva parte das ciências exatas trabalha com questões de predictibilidade e não 
é possível fazer inferências sobre o futuro sem uma base registrada com dados (PANCHENKO, 1994).

Os cadernos de um laboratório são indispensáveis para práticas científicas, pois uma nova observação deve levar em conta aquilo que foi registrado (LATOUR, 2011). Uma dedução com vistas a fundamentar teorias novas deve articular todos esses dados, produzir informações e gerar conhecimento. Em última instância, o arquivo é a matéria-prima do conhecimento científico e toda inovação tecnológica oficial é encaminhada aos registros de patentes cujos escritórios são imensos arquivos.

Uma das mais significativas inovaç̃êes tecnológicas da civilização atual foi o aumento na capacidade de armazenar arquivos. Muitas se beneficiaram com metodologias, tecnologias e profissionais no sentido de racionalizar o trâmite dos arquivos. A Memoteca Fink foi sem dúvida, no Brasil, uma das empresas que mais lucrou com o setor dos arquivos na esfera privada. Contudo, a Recall parece ter tomado seu espaço no mercado brasileiro. A Memoteca Fink, assim como suas concorrentes, se especializou nos arquivos correntes e intermediários. Esses arquivos estão ligados a uma memória mais imediata., Qual montante vale, no mercado, uma empresia de armazenamento de arquivos com sucesso? A empresa Iron Mountain, que negociou a Recall Holdings esse ano, atingiu a soma de dois bilhões de dólares (COMPETITION, 2016, p. 5).

A explosão do mercado dos arquivos se deu num contexto em que as máquinas digitais e os microprocessadores deixaram de ser exclusividade de unidades de inteligência dos governos para popularizar-se num novo mercado. Dentre os mais populares, incluem-se as memórias externas e internas, pendrives, softwares, hardwares, celulares androids, conteúdos de sites pagos, TV online, filmes online, músicas comercializadas na web, livros digitais, jogos virtuais, redes sociais, tablets, e uma infinidade de produtos tecnológicos. Os próprios mercados formais, como os mercados de capitais, os mercados financeiros, os mercados consumidores, e os mercados de serviços passaram ocupar uma ambiência digital, e as transações passaram a depender da tecnologia. 
Não foi aleatoriamente que Brothman (2001) apontou a possibilidade de uma aproximação entre o campo dos arquivos e dos negócios por meio das tecnologias. Para o autor, isso inclui repensar a utilização organizacional da memória eletrônica de longo prazo, promover inovações no design dos sistemas, na recuperação da informação e nos softwares de gestão de arquivística.

Para Brothman (2001) os arquivistas devem elaborar mecanismos mnemônicos junto a processos de aplicações dos mesmos, tendo em vista as interfaces entre os resíduos do passado e a atualização do presente, para atender o funcionamento eficaz da memória em antecipação das necessidades e utilizações futuras.

Um caso que ilustra a utilidade desses mecanismos mnemônicos em suporte digital é o arquivamento de estatísticas da North American Space Agency (NASA). No contexto da formação e uso da base mnemônica da NASA encontramos o seguinte relatório, publicado em 1995:

Descrição do Problema ou Sugestão: 0 esquema atual inclui arquivamento de estatísticas selecionadas (min., máx., media, - desvio padrão, e número de amostras) para cada TLM mnemônica para toda órbita, todo dia, todo mês, e missão à data. Essas escolhas podem ser um tanto arbitrária, e podem não ser nem necessárias, nem suficientes para necessidades típicas. É provável que seja ineficiente e improdutivo arquivar cada TLM mnemônica de forma idêntica. Pode ser mais benéfico e eficiente para FOT e/ou engenheiros de subsistemas definirem o arquivamento estatístico necessário em subsistema-por-subsistema e base mnemônica-por-mnemônica baseada em operações empíricas de voos em órbita no mundo real e em experiências de engenharia de sistemas de voo. Arquivando como definido poderia então ser colocado em funcionamento pelo sistema tendo por base as tabelas criadas por eles mesmos. No mínimo, o sistema poderia fornecer algumas opções pré-definidas das quais os usuários escolheriam para cada mnemônica. Por exemplo, é improvável que estatísticas arquivadas de temperaturas variando lentamente, frequências de oscilador ou tensões constantes de fontes de alimentação reguladas sejam idênticas às estatísticas arquivadas de quantidades que mudam rapidamente, como velocidades de roda de giroscópio, temperaturas de transmissor ou sensores de atitude. Recomendação do Promotor: Fornecer uma capacidade para arquivamento mnemônico exclusivo, incluindo minimamente várias opções dentre as quais os usuários possam escolher (NASA, 1995, tradução nossa)

Esses arquivos eletrônicos, que ocu- 
pam a memória artificial, podem ser valorados após um processo de avaliação que definirá o que será esquecido e o que poderá ser (re)lembrado. Assim, as práticas arquivísticas são essencialmente mnemônicas, porque instrumentalizam as pessoas e as instituições no sentido de ativarem suas memórias. Isso significa que a avaliação, na prática, define aquilo que será armazenado e ficará sob a custódia legal de uma instituição arquivística permanentemente. Portanto, a prática de avaliar como uma forma de constituição de fundos de arquivos eletrônicos ou arquivos tradicionais deve ser levada em consideração.

E como podemos entender a formação dos fundos de arquivo? Para pensarmos um arquivo e o processo de arquivar é possível fazê-lo por duas perspectivas: retrospectiva e prospectiva. Como abordado por Hofman (2007), a proposta retrospectiva direciona o olhar para trás, caracterizando a natureza de um arquivo e sua transmissão ao longo do tempo. Pela visão prospectiva, observa-se o processo de construção de um arquivo em uma organização, sendo o enfoque direcionado à criação, captura e seleção de registros.

Conforme tratado por Upward (2007), com base nas construções de Michel Foucault, o arquivo seria uma entidade diversa, que controla pensamentos e que nunca pode quebrar-se por completo, uma vez que está sempre pronto para desorganizar as formações discursivas que tem construído: 0 arquivo estaria vinculado às condições históricas de enunciados e ao conjunto dos discursos efetivamente pronunciados, que continua funcionando e se transforma através da história e mediante o aparecimento de outros discursos. Deste modo, as regras de um arquivo definiriam os limites e as formas possíveis de enunciação, conservação, reativação e apropriação (CASTRO, 2009).

Por meio destes entendimentos, observamos os arquivos a partir das formas de reconhecimento/definição/ validação das suas funções e dos múltiplos processos que lhe concederam um nome/lugar próprio. 0 arquivo seria um espaço definido a partir de 
um número finito de propriedades estáveis, isoláveis e articuladas umas sobre as outras. Esse lugar seria organizado por operações especulativas e classificatórias, por meio das quais seriam combinadas as ações de gestão e eliminação. Todavia, tal organização funcionalista não deve obscurecer as condições para novas possibilidades de enunciados dentro de uma cultura tecnológica, científica e política. Tais possibilidades permitem o tratamento do arquivo a partir de diversas associações que conduzem a transformações, intervenções e apropriações, apontando para novas formas de reconhecimento/definiçã̃o/validação.

Pelo viés prático da Arquivística, a relação entre o arquivo e a memória é estabelecida por meio do exercício de poder(es): os arquivos exercendo poder pelo que registram, pelo que não registram e pela forma como um registro é realizado. Para Ketellar (2007), os registros têm e são um poder.

Na visão de Cook (1998), os registros são produtos conscientes para criar ou servir a um propósito. Pelo.pensamento dos arquivos, o passado é controla- do, certas histórias são privilegiadas e outras marginalizadas. Verifica-se, portanto, que os arquivos podem ser, entendidos como sítios ativos onde o poder é negociado, constatado e confirmado (SCHWARTZ; COOK, 2002).

Na concepção de Murguia (2011, p. 29, tradução nossa), "o arquivo é sempre uma exterioridade, uma prótese, uma quantificação do documento; mas, sobretudo, é também um lugar e um espaço". O arquivo como lugar seria aquele vinculado à noção de disposição física dos documentos, onde reina qualquer tipo de ordem e exercício de poder. Tal visão se relaciona aos arquivos institucionalizados (públicos e privados), os quais passaram a ser reconhecidos como lugares de memória. Já a noção de espaço aponta para os movimentos e deslocamentos que levam a diversos tipos de exterioridade, materialidade e circulação documental. Tais dinâmicas são articuladas por meio de fazeres ou trajetórias de ordem estratégica e tática: o lugar seria onde as coisas devem estar e o espaço onde elas podem estar.

A ampliação conceitual proposta por 
Murguia (2017) sobre os lugares de memória proporciona entendimentos a respeito dos processos de racionalização (dessacralização e desmistificação) que alocam à circunscrição de um lugar como algo próprio. Quando o autor lança essas questões, pelo viés dos processos de institucionalização dos arquivos, leva-nos ao entendimento desses lugares de memória também como um não-lugar, uma vez que as manifestações temporais, como a memória, são formas de apropriações e emergências criadas nas fissuras desejadas pelo exercício de um poder institucional. Tais questões podem ser mais bem apreendidas se compreendermos seus limites ou as fronteiras que possibilitam compreensões sobre a relação entre arquivos e memória.

Na visão de Piggott (2007), essa relação é uma questão incontestável, que pode ser percebida desde Jenkinson (1922) até as considerações de uso bastante comum da ideia de lugar de memória, proposta por Nora (1993). Piggott (2007, p. 410, tradução nossa) apresenta que ao longo dos últimos quatro séculos as estruturas corpora- tivas e o Estado têm necessitado, cada vez mais, de uma memória. Este fato pode serverificado de forma mais pontual desde a Nação-Estado, e de toda sua maquinaria, que passou a descobrir que "os registros não eram uma conveniência artificial, mas um capacitador indispensável e muito exato da lembrança organizada". No entanto, o autor enfatiza o exagero dessa conexão ao problematizar o peso que algumas afirmações têm sobre a ideia de que a base documental da memória coletiva de uma nação teria como alicerce a conservação de documentos (representação do passado humano) em lugares como os arquivos.

O autor chamou a atenção sobre a distinção entre a lembrança e o esquecimento, fator que, segundo ele, tem se desvanecido. Sobre isso, destaca que cada vez mais os arquivos, as bibliotecas e os museus passam a ser considerados coletivamente como instituições de memória. Como pontua, no setor do patrimônio cultural da Austrália e de outros países, os estudos culturais e de memória dentro dessas três instituições desconsideram 
a importante distinção que se coloca através da dialética da memória (lembrança e esquecimento).

Por meio desses estudos, os contrates entre a natureza e a significância da memória não estão presentes no interior desses lugares, mas o que é distinguido são os "mitos e crenças comunicados de maneira oral por uma parte, e os objetos, artefatos e documentos fisicamente mais duráveis, por outra" (PICCOTT, 2007, p. 416, tradução nossa). O Programa Memória do Mundo (1992), da Organização das Nações Unidas para a Educação, a Ciência e a Cultura (Unesco), permite o registro de materiais arquivísticos e impressos sendo exemplo da ampliação dessas manifestações em âmbito internacional. Por meio desse programa, percebemos alguns movimentos que tendem para uma sobrevalorização da preservação de certa memória através da seleção de determinados registros e sua instituição como patrimônio documental; um patrimônio que carregaria a incumbência de ser o suporte e objetificação da memória do mundo.

Uma 'articulação mais ampla e quali- ficada para a relação entre memória, registro (s) e arquivo (s) na atualidade seria possível, por exemplo, através, dos trabalhos desenvolvidos por Cook (2001), os quais colocam que a importância do resíduo documental está não somente vinculado à memória da sociedade, mas também à revelação das inter-relações entre o cidadão-estado e seus equivalentes, como corporações, corpos não governamentais, instituições, organizações religiosas e outras. Em outros termos, essa visão permite-nos considerar não somente os registros das transações administrativas, mas as tantas informações e memórias "circunscritas" em diferentes suportes e/ou realizadas em diversas manifestações (PICCOTT, 2007).

Para Piggott (2007, p: 436), as operações que têm por intenção tomar a memória como objeto estão, geralmente, destinadas ao fracasso. Em sua opinião, tais ações que visam recordar o oco ou a "presença ativa das coisas ausentes" tendem a "profanar e desmoralizar; golpear tanto simbólica quanto fisicamente" o traçado dos resíduos do passado. 
Como colocaria Certeau (2004, p. 189), "o que impressiona mais, aqui, é o fato de os lugares vividos serem como presenças de ausências". Na concepção de Murguia (2011), os arquivos compreendidos nesses aspectos seriam, portanto, um símbolo e um lugar de memória; simbolizariam tanto o passado por meio das buscas das origens quanto o poder do Estado moderno através de diversos lugares como as cidades, instituições civis e oficiais.

Um fator importante nessas reflexões são os percursos de/para racionalização das memórias por meio de estratégias, agenciamentos e exercício de múltiplos poderes para a institucionalização, estabilização e enquadramento de espaços/ambiências como lugares pré-estabelecidos. A crescente definição, valorização e preservação desses lugares e de seus conteúdos (materiais e simbólicos) ressalta a ideia da preservação pelo viés da perda, sem que pareça ser necessário colocar em discussão as várias (res)significações valorativas, os esquecimentos e os movimentos que estabelecem a relaç̧ão entre arquivos e memória como sinônimos, "de maneira muito confiada e muito frequentemente" (PICCOTT, 2007, p. 405).

De acordo com o que foi exposto, dentre os eixos possíveis decorrentes da associação entre a memória e os arquivos estão: arquivos jurídico-administrativos - memória institucional; patrimônio arquivístico - memória histórica e cultural; produtos e serviços info-arquivísticos - memória digital. Esse último eixo tem sido pouco explorado pela literatura, que tem se concentrado na gestão documental nas esferas pública e privada, sem considerar o arquivo como dispositivo de poder institucionalizado (não somente estatal), que sustenta o funcionamento dos mercados de empresas de armazenamento que exploram práticas mnemônicas com valoreś econômicos bilionários, tal como assinalamos no caso da negociação entre a Iron Mountain e a Recall. Há, pelo menos no mercado, uma clara distinção entre o campo da memória imediata e da mediata: a primeira ligada à gestão documental, e a segunda com o tratamento e a mediação. O que indica o 
nosso entendimento de que a articulação/vinculação entre a memória se dá, ao menos no campo da Arquivística, com base em suas epistemes científicas, as quais são desdobramentos ou acomodam as epistemes jurídica, histórica e administrativa. Neste sentido, tais questões colocam na pauta dos campos teóricos, epistemológicos e práticos, o imperativo da explicitação, de forma proporcional e honesta, das conjunturas e intenções relativas à associação entre memória e arquivo, sem utilizar o conceito de memória apenas como lobby ou propaganda.

\section{Conclusão}

A memória não é o arquivo, mas as práticas mnemônicas coincidem, em certa medida, com as práticas arquivísticas. Portanto, a partir dessas práticas alocadas nos saberes arquivísticos, como, o arranjo, a descrição e a avaliação, os documentos podem vir a ser ativadores da memória. As relações possíveis entre memória e arquivo se estabelecem no campo das práticas mnemônicas e,com a tecnologia, também dos mecanismos mnemônicos. Na medida em que os arquivos são materialidades do passado, eles podem atualizar a memória de uma pessoa, ou conjunto de pessoas, frente às demandas do presente. Consideramos, portanto, que os arquivos compõem uma parte significativa das bases que serão parte da memória praticada de uma instituição, família, cidadão ou sociedade. Entretanto, é preciso considerar que essas bases podem ser compreendidas no âmibito de atuação técnica que se correlaciona com os saberes e as práticas da arquivística. 


\section{Referências}

BROTHMAN, Brien. The past that archives keep: memory, history, and the preservation of archival records. Archivaria, n.51, Ottawa, 2001: p. 48-80.

CASANOVA, Eugenio. Archivistica. 2 ed. Siena: Stab. Arti Crafiche Lazzeri, 1928

Disponível em: $<$ http://www.icar.beniculturali.it/biblio/pdf/EuCa/totalCasanova.pdf>. Acesso em: 10 ago. 2016.

CASTRO, Edgardo. Vocabulário de Foucault: um percurso pelos temas, conceitos e autores. Belo Horizonte: Autêntica Editora, 2009.

CERTEAU, Michel de. Ainvenção do cotidiano: 1. Artes de fazer. 10 ed. Petrópolis: Vozes, 2004.

COMPETITION AND MARKETS AUTHORITY. A report on the completed acquisition by Iron Mountain Incorporated of Recall Holdings Limited. Londres, 16 jun 2016. Disponivel em: <https://assets. publishing service.gov.uk/media/57628172ed915d3cfd000058/iron-mountain-recall-final-report.pdf>. Acesso em: 20 jul. 2016.

COOK, Terry. Archival science and postmodernism: new formulations for old concepts. Archival Science: International Journal on Recorded Information, v. 7, n.7, Dordrecht, 2001, p. 3-24.

COOK, Terry. Arquivos pessoais e arquivos institucionais: para um entendimento arquivístico comum da formação da memória em um mundo pós-moderno. Estudos Históricos, v.11, n, 21, Rio de Janeiro, 1998, p. 129-149. Disponível em: <http://bibliotecadigital.fgv.br/ojs/index.php/ reh/article/view/2062/1201>. Acesso em: 12 jul. 2016.

DODEBEI, Vera; COUVEIA, Inês. Memória do futuro no ciberespaço: entre lembrar e esquecer. DataCramaZero-Revista de Ciência da Informação, v.9, n.5, Rio de Janeiro, out. 2008, p. 00. Disponivel em: <http://www.dgz.org.br/out08/F___art.htm>. Acesso em: 14 set. 2010.

DURANTI, Luciana. Archive as a place. Archives \& Social Studies - A Journal of Interdisciplinary Research, v.1, n.0, Cartagena, 2007, p. 445-466. Disponível em: <http://archivo.cartagena.es/ files/36-165-DOC_FICHERO1/0'7-duranti_archives.pdf>. Acesso em: 15 mai. 2016. 
HOFMAN, Hans. El archivo. In: MCKEMMISH, Sue et al. (Orgs.). Archivos: gestión de registros en sociedad. Cartagena: Concejalía de Cultura, 2007, p. 191-226.

KETELAAR, Eric. Cestión de registros y poder social. In: MCKEMMISH, Sue. et al. (Orgs.). Archivos: gestión de registros en sociedad. Cartagena: Concejalía de Cultura, 2007, p. 379-404.

JENKINSON, Hilary. A Manual of Archive Administration. Oxford: Clarendon Press, 1922

LATOUR, Bruno. Ciência em ação: como seguir cientistas e engenheiros sociedade afora. Tradução de Ivone C. Benedetti. 2. ed. São Paulo: Unesp, 2017.

LE GOFF, Jacques. História e memória. 5 ed. Campinas: Unicamp, 2003.

LONG, Ceorge. Political Dictionary; forming a work of universal reference, both constitutional and legal; and embracing the terms of civil administration, of political economy and social relations, and od all the more important statistical departaments of finance and commerce. Londres: Charles Knight and CO., 1845. v.1.

MENESES, UIpiano Bezerra de. Os paradoxos da memória. In: MIRANDA, Danilo Santos de (Org.). Memória e cultura: a importância da memória na formação cultural humana. São Paulo: Edições SESC/SP, 2007, p. 13-33.

MURCUIA, Eduardo Ismael. Archivo, memoria e história: cruzamientos e abordajes. Íconos Revista de Ciencias Sociales, n.41, Quito, 2011, p. 17-37. Disponível em: <http://revistas.flacsoandes.edu.ec/iconos/article/view/387/380 > . Acesso: 10 jul. 2016.

NORA, Pierre. Entre Memória e História. A problemática dos lugares. Projeto História-Revista do Programa de Estudos dos Pós-Graduados em História, v.10, n:10, São Paulo, 1993, p.7-28.

NASA (North American Space Agency). Report. Preliminary Design Review. Organization Mission Operations Manager/505, 1995. Disponivel em: <http://edhs1.gsfc.nasa.gov/waisdata/ complete/hold/PDR_Rids/121.pdf>. Acesso em: 15 mai. 2016.

PANCHENKO, Dimitri. Thales's Prediction of a Solar Eclipse. Journal for the History of Astronomy, n.25, 1994, p. 275. Disponível em:<http://articles.adsabs.harvard.edu/ full/1994]HA...25..275P>. Acesso em: 12 jun. 2016. 
PICGOTT, Michael. Archivos y memoria. In: MCKEMMISH, Sue. et al. (Orgs.). Archivos: gestión de registros en sociedad. Cartagena: Concejalía de Cultura, 2007, p. 405-447.

RAMINCEN, Jakob von. Von der Registratur, Vnd Jren Cebäwen vnd Regimenten, deßgleichen von jhren Bawmeistern vnd Verwaltern vnd jrer qualificationen vnd habitibus, Heidelberg, 1571. Disponivel em: $<$ https://bildsuche.digitale-sammlungen de/index.html?c=viewer\&lv= 1 \&bandnummer $=$ bsb00010487 \&pimage $=00001$ \&suchbegriff $=\& l=$ de $>$. Acesso em: 29 nov 2016

SCHWARTZ, Joan M.; COOK; Terry. Archives, records, and power: the making of modern memory. Archival Science: International Journal on Recorded Information, v.2, n. 1, Dordrecht, 2002, p. $1-19$.

UPWARD, Frank. El contínuo de lós registros. In: MCKEMMISH, Sue et al. (Orgs.). Archivos: gestión de registros en sociedad. Cartagena: Concejalía de Cultura, 2007, p. 275-307. 